\title{
Repeat pulmonary resection for lung malignancies does not affect the postoperative complications: a retrospective study
}

\author{
Nozomu Motono* ${ }^{*}$, Shun Iwai, Yoshihito lijima, Katsuo Usuda and Hidetaka Uramoto
}

\begin{abstract}
Background: Although repeat pulmonary resection (RPR) for multiple lung cancer has been performed for nonsmall cell lung cancer and metastatic lung tumor, with the prognostic benefit detailed in several reports, the risk of RPR has not been well analyzed.

Methods: Patients with lung malignancies who underwent complete resection at Kanazawa Medical University between January 2010 and October 2019 were analyzed. The relationship between postoperative complications and preoperative and perioperative factors was analyzed. Postoperative complications were categorized into five grades according to the Clavien-Dindo classification system.

Results: A total of 41 patients who were received RPR were enrolled in this study. Primary lung tumor was found in 31 patients, and metastatic lung tumor was found in 10 patients. The postoperative complication rate of the first operation was $29 \%$, and that of the second operation was $29 \%$. While there were no significant factors for an increased incidence of postoperative complication in a multivariate analysis, an operation time over $2 \mathrm{~h}$ at the second operation tended to affect the incidence of postoperative complication $(p=0.06)$. Furthermore, the operation time was significantly longer $(p=0.02)$ and wound length tended to be longer $(p=0.07)$ in the ipsilateral group than in the contralateral group. The rate of postoperative complications and the length of the postoperative hospital stay were not significantly different between the two groups.
\end{abstract}

Conclusion: RPR is safely feasible and is not associated with an increased rate of postoperative complications, even on the ipsilateral side.

Keywords: Repeat pulmonary resection, Multiple lung cancer, Postoperative complication, Video-assisted thoracic surgery

\section{Background}

Repeat pulmonary resection (RPR) for multiple lung cancer (MLC) has been performed for non-small cell lung cancer (NSCLC) and metastatic lung tumor, and the prognostic benefit has been described in several reports [1-9]. However, the risk of RPR has not been well

*Correspondence: motono@kanazawa-med.ac.jp

Department of Thoracic Surgery, Kanazawa Medical University, 1-1

Daigaku, Uchinada, Ishikawa 920-0293, Japan analyzed. Although the mortality for patients who have undergone RPR was reported to range from 5 to $11 \%$ in previous reports [10-14], the mortality and complication rate for RPR have evolved thanks to recent improvements in surgical procedures.

Video-assisted thoracic surgery (VATS) for NSCLC patients has been widely adopted and the benefits of this approach have been reported [15-20]. Previous studies have shown that VATS is less painful, has a shorter hospital stay, has less reduced inflammatory-immune 
response, and is associated with postoperative maintenance of respiratory function compared with thoracotomy [17-19]. However, the relationship between the VATS approach and the rate of postoperative complications is not clear.

In the present study, we evaluated the perioperative variables and the risk of RPR in MLC patients.

\section{Methods}

\section{Patients}

Eight hundred and eighty-eight patients with lung malignancies who underwent complete resection in Kanazawa Medical University between January 2010 and October 2019 were identified. Among these, 468 NSCLC patients and 10 metastatic lung tumor patients had available data. Forty-one patients underwent repeat pulmonary resection, and 437 patients underwent single pulmonary resection. These patients were enrolled in the present retrospective study and analyzed.

About collected data, the clinical factors included the sex, age, smoking history, comorbidities, and the carcinoembryonic antigen (CEA), vital capacity as percent of predicted (\%VC), forced expiratory volume in $1 \mathrm{sec}-$ ond percent as percent of forced vital capacity (FEV1\%), the side of lung tumor, and the diagnosis of lung tumor. The smoking history was evaluated using the Brinkman index, which is calculated as the number of cigarettes smoked per day multiplied by the number of years for which the subject has smoked [21]. The perioperative factors included the wound length, operative approach, operative procedure, and operation time. The operative approach was divided into three categories: complete VATS (C-VATS; surgery was only performed to provide a monitoring view); hybrid VATS (H-VATS; surgery was combined with direct vision without rib spreading); and thoracotomy. Postoperative complications were categorized into five grades according to the Clavien-Dindo classification system [22].

The present study was conducted in accordance with the amended Declaration of Helsinki. The Institutional Review Boards of Kanazawa Medical University approved the protocol (approval number: I392), and written informed consent was obtained from all of the patients. All data was anonymised before its use.

\section{Statistical analyses}

The cumulative survival rates were calculated by the Kaplan-Meier method, and survival curves were compared using a log-rank test. Multivariate analyses using a stepwise logistic regression model was conducted to determine the risk factors for postoperative complication. All statistical analyses were two-sided, and $p$ values of $<0.05$ were considered to indicate statistical significance. The statistical analyses were conducted using the JMP software program (Version 13.2; SAS Institute Inc., Cary, NC, USA).

The present study was conducted in accordance with the amended Declaration of Helsinki. The Institutional Review Boards of Kanazawa Medical University approved the protocol (approval number: I392), and written informed consent was obtained from all of the patients.

\section{Results}

\section{Patient characteristics}

The clinicopathological characteristics of the 41 patients who received RPR in the present study are listed in Table 1. The median follow-up time was

Table 1 Patient characteristics

\begin{tabular}{ll}
\hline 1st age (years) & $68(37-80)$ \\
2nd age (years) & $70(37-81)$ \\
Gender (male/female) & $31 / 10$ \\
Smoking index & $160(0-2000)$ \\
Ipsilateral/contralateral & $13 / 28$ \\
$\mathrm{R} \rightarrow \mathrm{R}$ & 12 \\
$\mathrm{R} \rightarrow \mathrm{L}$ & 17 \\
$\mathrm{~L} \rightarrow \mathrm{L}$ & 2 \\
$\mathrm{~L} \rightarrow \mathrm{R}$ & 10 \\
Primary/metastatic & $31 / 10$ \\
1st \%VC & $102.9(63.1-140)$ \\
1st FEV $1.0 \%$ & $73.3(40.8-98)$ \\
1st approach (C/H/T) & $11 / 29 / 1$ \\
1st operative procedure (Part/Seg/Lob) & $17 / 1 / 23$ \\
1st wound length (mm) & $7(3-20)$ \\
1st operation time (min) & $166(46-580)$ \\
1st postoperative complication (present/absent) & $12 / 29$ \\
1st Clavien-Dindo grade (0/1/2/3a) & $29 / 1 / 5 / 6$ \\
2nd \%VC & $87.4(60.5-122.7)$ \\
2nd FEV $1.0 \%$ & $70.3(43.1-86)$ \\
2nd approach(C/H/T) & $14 / 23 / 4$ \\
$\Delta \%$ VC & $-12(-42.2-5.8)$ \\
$\Delta F E V_{1.0} \%$ & $-2.6(-30.1-17.2)$ \\
2nd operative procedure (Part/Seg/Lob) & $27 / 7 / 7$ \\
2nd wound length (mm) & $6(3-20)$ \\
2nd operation time & $126(46-501)$ \\
2nd postoperative complication (present/absent) & $12 / 29$ \\
2nd Clavien-Dindo grade (0/1/2/3a) & $29 / 0 / 4 / 8$ \\
1st postoperative hospital stay (days) & $15(4-36)$ \\
2nd postoperative hospital stay (days) & $12(4-62)$ \\
Interval from 1st to 2nd operation (days) & $406(28-4529)$ \\
\hline & \\
\hline &
\end{tabular}

$\% \mathrm{VC}$, predictive vital capacity; $\mathrm{FEV}_{10} \%$, forced expiratory volume in 1 second/ forced vital capacity ratio; $\mathrm{C}$, complete video-assisted thoracic surgery; $\mathrm{H}$, hybrid video-assisted thoracic surgery; T, thoracotomy; Part, partial resection; Seg, segmentectomy; Lob, lobectomy; $\Delta \% \mathrm{VC}$, rate of $2 \mathrm{nd} \% \mathrm{VC}$ per 1 st $\% \mathrm{VC} ; \Delta \mathrm{FEV}{ }_{1.0} \%$, rate of 2 nd FEV ${ }_{1.0} \%$ per 1 st $\mathrm{FEV}_{1.0} \%$ 
1457 days (range: 162 to 5758 days). Thirty-one patients were men, and the median age at the first operation was 68 years old, while that at the second operation was 70 years old. The median Brinkman index was 160, and ipsilateral resection was performed in 13 patients. Primary lung tumor was found in 31 patients and metastatic lung tumor in 10 patients. The median $\% \mathrm{VC}$ at the first operation was $102.9 \%$, and that at the second operation was $87.4 \%$. The median FEV1\% at the first operation was $73.3 \%$, and that at the second operation was $70.3 \%$.

\section{Perioperative factors}

The first operative approach was C-VATS in 11 patients, H-VATS in 29, and thoracotomy in 1 . The second operative approach was C-VATS in 14 patients, H-VATS in 23 , and thoracotomy in 4 . The median wound length of the first operation was $7 \mathrm{~mm}$, and the median operation time was $166 \mathrm{~min}$. The median wound length of the second operation was $6 \mathrm{~mm}$, and the median operation time was $126 \mathrm{~min}$. Sublobar resection in 18 patients and lobectomy in 23 was performed at the first operation. Sublobar resection in 34 patients and lobectomy in 7 was performed at the second operation. The postoperative complication rate of the first operation was $29 \%$, and the postoperative complications were classified as Clavien-Dindo grade 0 in 29 patients, grade I in 1, grade II in 5 , and grade IIIa in 6 . All six patients with grade IIIa complications had prolonged air leakage and underwent pleurodesis. The postoperative complication rate of the second operation was $29 \%$, and the postoperative complications were classified as Clavien-Dindo grade 0 in 29 patients, grade I in 0 , grade II in 4, and grade IIIa in 8. All eight patients with grade IIIa complications had prolonged air leakage and underwent pleurodesis. The incidence of postoperative complications in the RPR and single pulmonary resection (SPR) groups was not significantly different (data not shown; RPR: SPR $=29 \%: 26 \%$, $p=0.71$ ). The median postoperative hospital stay after the first operation was 15 days, while that after the second operation was 12 days.

\section{Bivariate analyses}

The relationship between patients' characteristics and perioperative factors and postoperative complications after RPR is shown in Table 2. Although the gender, age, smoking history, operative side, operative procedure, $\% \mathrm{VC}, \mathrm{FEV} 1 \%$, approach at the second operation, and duration of the second operation were analyzed, these factors did not significantly affect the incidence of postoperative complications.
Table 2 Bivariate analysis of relationship between patients characteristics and perioperative factors and postoperative complication

\begin{tabular}{|c|c|c|}
\hline & Complication \% (n) & $p$ value \\
\hline \multicolumn{3}{|l|}{ Gender } \\
\hline Male & $29(9 / 31)$ & \multirow[t]{2}{*}{0.95} \\
\hline Female & $30(3 / 10)$ & \\
\hline \multicolumn{3}{|l|}{ Age } \\
\hline$<70$ years & $22(4 / 18)$ & \multirow[t]{2}{*}{0.38} \\
\hline$\geqq 70$ years & $35(8 / 23)$ & \\
\hline \multicolumn{3}{|l|}{ Smoking history } \\
\hline Never & $20(4 / 20)$ & \multirow[t]{2}{*}{0.21} \\
\hline Current/former & $38(8 / 21)$ & \\
\hline \multicolumn{3}{|l|}{ Side } \\
\hline Ipsilateral & $31(4 / 13)$ & \multirow[t]{2}{*}{0.88} \\
\hline Contralateral & $29(8 / 28)$ & \\
\hline \multicolumn{3}{|c|}{ 1st operative procedure } \\
\hline Part & $29(5 / 17)$ & \multirow[t]{2}{*}{0.98} \\
\hline Seg/Lob & $29(7 / 24)$ & \\
\hline \multicolumn{3}{|c|}{ 1st postoperative complication } \\
\hline Absent & $31(9 / 29)$ & \multirow[t]{2}{*}{0.69} \\
\hline Present & $25(3 / 12)$ & \\
\hline \multicolumn{3}{|l|}{ 2nd \%VC } \\
\hline$<80$ & $20(3 / 15)$ & \multirow[t]{2}{*}{0.69} \\
\hline$\geqq 80$ & $34(9 / 26)$ & \\
\hline \multicolumn{3}{|l|}{ 2nd FEV $1.0 \%$} \\
\hline$<70$ & $25(5 / 20)$ & \multirow[t]{2}{*}{0.56} \\
\hline$\geqq 70$ & $33(7 / 21)$ & \\
\hline \multicolumn{3}{|l|}{ 2nd approach } \\
\hline C & $29(8 / 27)$ & \multirow[t]{2}{*}{0.94} \\
\hline$H / T$ & $28(4 / 14)$ & \\
\hline \multicolumn{3}{|c|}{ 2nd operative procedure } \\
\hline Part & $29(8 / 27)$ & \multirow[t]{2}{*}{0.94} \\
\hline Seg/Lob & $28(4 / 14)$ & \\
\hline \multicolumn{3}{|l|}{ 2nd operation time } \\
\hline$<2 \mathrm{~h}$ & $20(4 / 20)$ & \multirow[t]{2}{*}{0.67} \\
\hline$\geqq 2 \mathrm{~h}$ & $38(8 / 21)$ & \\
\hline
\end{tabular}

Part, partial resection; Seg, segmentectomy; Lob, lobectomy; \%VC, predictive vital capacity; FEV $1.0 \%$, forced expiratory volume in 1 second/forced vital capacity ratio; $\mathrm{C}$, complete video-assisted thoracic surgery; $\mathrm{H}$, hybrid videoassisted thoracic surgery; $T$, thoracotomy

\section{Multivariate analyses}

Our multivariate analysis of postoperative complications examined the joint effects of the gender, age, smoking history, operative side, procedure for the first operation, postoperative complications after the first operation, $\% \mathrm{VC}$ at the second operation, FEV1\% at the second operation, approach at the second operation, procedure for the second operation, and duration of the second operation. There were no significant factors affecting the incidence of postoperative complications (Table 3). 
Table 3 Multivariate analysis for postoperative complication

\begin{tabular}{lcll}
\hline & OR & $95 \% \mathrm{Cl}$ & $p$ value \\
\hline Gender (male) & 1.15 & $0.17-7.65$ & 0.87 \\
Age ( $\geqq 70$ years) & 1.67 & $0.23-12.01$ & 0.61 \\
Smoking history (Curr + Former) & 4.27 & $0.66-27.58$ & 0.12 \\
Side (ipsilateral) & 1.08 & $0.19-6.13$ & 0.92 \\
1st Operative procedure (Seg + Lob) & 1.92 & $0.25-14.74$ & 0.52 \\
1st Postoperative complication (present) & 0.36 & $0.04-3.07$ & 0.35 \\
2nd \%VC (<80\%) & 0.53 & $0.08-3.35$ & 0.50 \\
2nd FEV $1.0 \%(<70 \%)$ & 0.22 & $0.03-1.68$ & 0.14 \\
2nd approach (H+T) & 0.52 & $0.06-4.03$ & 0.53 \\
2nd operative procedure (Seg + Lob) & 0.28 & $0.02-2.74$ & 0.27 \\
2nd operation time ( $\geqq 2$ h) & 12.65 & $0.86-184.77$ & 0.06 \\
\hline
\end{tabular}

Curr, current; \%VC, predictive vital capacity; $\mathrm{FEV}_{10} \%$, forced expiratory volume in 1 second/forced vital capacity ratio; Seg, segmentectomy; Lob, lobectomy $\mathrm{H}$, hybrid video-assisted thoracic surgery; $\mathrm{T}$, thoracotomy,

\section{Sub-analyses}

The relationship between the operative side (ipsilateral or contralateral) and perioperative factors was analyzed (Table 4). The operation time was significantly longer $(p=0.02)$, and the wound length tended to be longer $(p=0.07)$ in the ipsilateral group than in the contralateral group. The rate of postoperative complications and the length of the postoperative hospital stay were not significantly different between the two groups.

\section{Survival analyses}

The overall survival from the first operation is shown in Fig. 1. The 10 -year overall survival was $84 \%$. The overall survival from the second operation is shown in Fig. 2. The 8-year overall survival was $78 \%$.

\section{Discussion}

We evaluated the risk of RPR for MLC in the present study. RPR was not found to be associated with the risk of postoperative complications, and there was no perioperative mortality. The incidence of postoperative complications with RPR was reported to range from 19 to $33 \%$ in previous studies $[1,3,4,9,10]$. Although the incidence

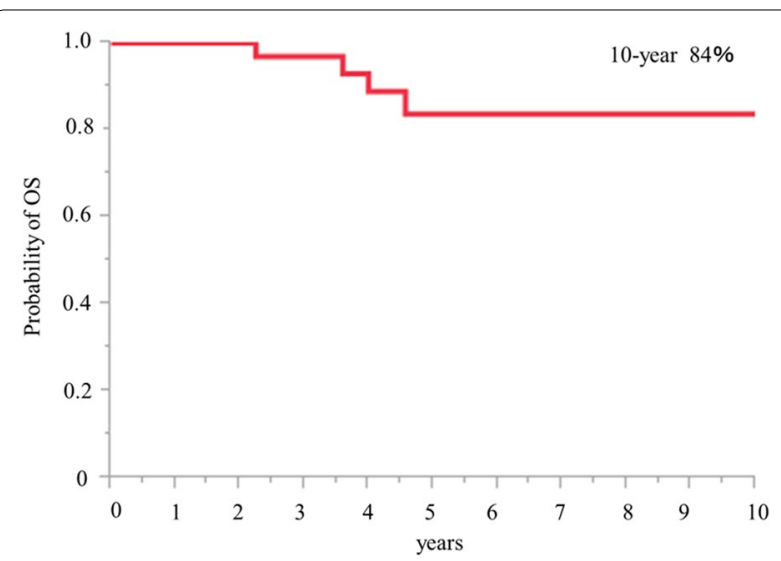

Fig. 1 Overall survival after 1st operation is shown. 10-year survival rate is $84 \%$

of postoperative complications at the second operation in the present study was $29 \%$, all patients with postoperative complications of grade IIIa had air leakage that required pleurodesis. The rate of other complications classified as grades I and II was $14 \%$ at the first operation and $9 \%$ at the second operation. These findings indicate that severe postoperative complications were relatively rare. The VATS approach for managing lung malignancies has been widely adopted and is reported to be less invasive than thoracotomy [15-20]. Because both the first and second operations were performed via the VATS approach in most cases in the present study, it might have been affected less invasive and physical function maintenance.

In previous studies, the mortality separated by operative procedure was reported; the mortality rate was $34 \%$ for pneumonectomy, $7 \%$ for lobectomy, $0 \%$ for segmentectomy, and $6 \%$ for partial resection [10]. The mortality rate might have been lower than in previous studies because there were more cases of partial resection and segmentectomy than lobectomy at the second operation in the present study. Although cases of sublobar resection accounted for more than $80 \%$ for second operations, the 8-year overall survival was $78 \%$, suggesting that sublobar resection might have a good

Table 4 Sub-analysis of relationship between operative side and perioperative factors

\begin{tabular}{|c|c|c|c|}
\hline & Ipsilateral & Contralateral & $p$ value \\
\hline 2nd operation time & $151(68-315)$ & $110(46-501)$ & 0.02 \\
\hline 2nd postoperative complication (present/absent) & $4 / 9$ & $8 / 20$ & 0.88 \\
\hline 2nd wound length (mm) & $8(4-20)$ & $5(3-15)$ & 0.07 \\
\hline 2nd approach $(\mathrm{C} / \mathrm{H} / \mathrm{T})$ & $3 / 7 / 3$ & $11 / 16 / 1$ & 0.12 \\
\hline 2nd operative procedure(Part/Seg/Lob) & $8 / 2 / 3$ & $19 / 5 / 4$ & 0.78 \\
\hline 2nd postoperative hospital stay (days) & $12(4-62)$ & $12(4-27)$ & 0.98 \\
\hline
\end{tabular}

$\mathrm{C}$, complete video-assisted thoracic surgery; $\mathrm{H}$, hybrid video-assisted thoracic surgery; $\mathrm{T}$, thoracotomy; Part, partial resection; Seg, segmentectomy; Lob, lobectomy 


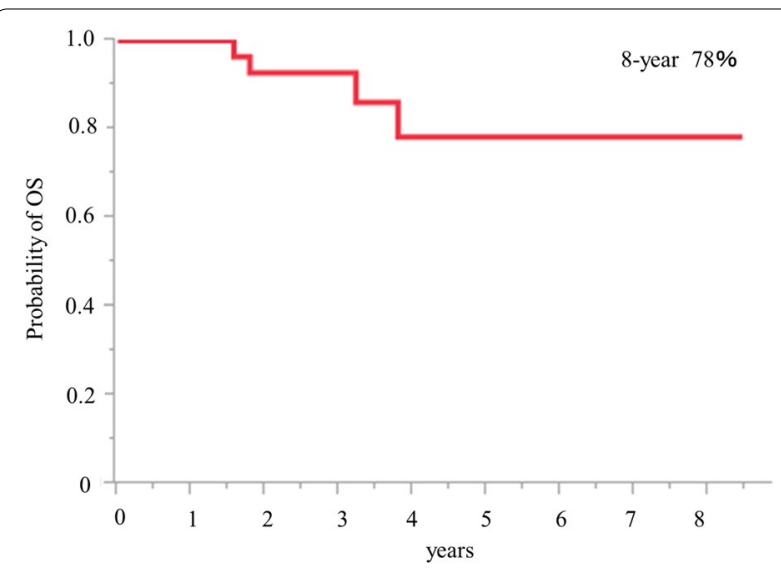

Fig. 2 Overall survival after 2 nd operation is shown. 8-year survival rate is $78 \%$

prognosis. Furthermore, sublobar resection might maintain the respiratory function and enable a third round of pulmonary resection.

RPR has diagnostic and therapeutic implications. The prevalence of a second malignancy in lung cancer patients investigated in previous studies was reported $1.87-2.41 \%$ [23, 24]. Although a histological examination is necessary for cases of metastasis or second primary lung cancer, the histological pattern may have changed in relapse tumors. Molecular assessments, such as gene array analyses or patterns of loss of heterozygosity, are useful for the identification of the independence of lung primaries, underscoring the importance of obtaining acceptable specimens. Furthermore, favorable outcomes were reported for select stage IV NSCLC patients who received complete resection of both the primary lung tumor and metastasis, such as solitary adrenal gland, brain or contralateral lung metastasis [25-27].

A previous study showed that an operation time exceeding two hours was a predictor of postoperative complications [10]. In the present study, an operation time exceeding two hours tended to increase the risk of postoperative complications in our multivariate analysis. Although ipsilateral resection for MLC had a significantly longer operation time than contralateral resection, the incidence of postoperative complications was not significantly different between ipsilateral and contralateral resection $(p=0.88)$. Therefore, ipsilateral RPR itself might be not predictor of postoperative complications.

The present study was associated with several limitations. First, the study was retrospective in nature and potentially involved unobserved cofounding and selection biases. Second, our study was performed at a single institution, and the study population was relatively small.

\section{Conclusions}

RPR is safely feasible and is not associated with an increased rate of postoperative complications, even on the ipsilateral side. RPR might improve the prognosis, and patient selection is important.

\section{Abbreviations}

RPR: Repeat pulmonary resection; MLC: Multiple lung cancer; NSCLC: Nonsmall cell lung cancer; VATS: Video-assisted thoracic surgery; CEA: Carcinoembryonic antigen; \%VC: Vital capacity as percent of predicted; FEV1\%: Forced expiratory volume in 1 second percent as percent of forced vital capacity: C-VATS: Complete video-assisted thoracic surgery; H-VATS: Hybrid videoassisted thoracic surgery; SPR: Single pulmonary resection.

\section{Acknowledgements}

Not applicable.

\section{Authors' contributions}

All authors have read and approved the manuscript. N. M. performed the research, collected and analyzed the data and wrote the paper. S. I., Y.I, and K. U. contributed to sample collection. H. U. contributed to supervision of this study and revision of the manuscript. All authors read and approved the final manuscript.

\section{Funding}

This study has not been funded.

\section{Availability of data and materials}

The datasets used and/or analysed during the current study are available from the corresponding author on reasonable request.

\section{Declarations}

\section{Ethics approval and consent to participate}

The present study was conducted in accordance with the amended Declaration of Helsinki. The Institutional Review Boards of Kanazawa Medical University approved the protocol (approval number: 1392), and written informed consent was obtained from all of the patients.

\section{Consent to publish}

Not applicable.

\section{Competing interests}

The authors declare that they have no competing interests.

Received: 14 August 2020 Accepted: 24 March 2021

Published online: 01 April 2021

References

1. Finley DJ, Yoshizawa A, Travis W, Zhou Q, Seshan VE, Bains MS, et al. Predictors of outcomes after surgical treatment of synchronous primary lung cancers. J Thoac Oncol. 2010;5:197-205.

2. Liu M, He W, Yang J, Jiang G. Surgical treatment of synchronous multiple primary lung cancers: a retrospective analysis of 122 patients. J Thorac Dis. 2016:8:1197-204.

3. Riquet M, Cazes A, Pfeuty K, Ngabou UD, Foucault C, Dujon A, et al. Multiple lung cancers prognosis: what about histology? Ann Thorac Surg. 2008;86:921-6.

4. Yang H, Sun Y, Yao F, Yu K, Gu H, Hah B, et al. Surgical therapy for bilateral multiple primary lung cancer. Ann Thorac Surg. 2016;101:1145-52.

5. Matsubara T, Toyokawa G, Kinoshita F, Haratake N, Kozuma Y, Akanime T, et al. Safety of simultaneous bilateral pulmonary resection for metastatic lung tumors. Anticancer Res. 2018;38:1715-9. 
6. Matsumoto T, Hasegawa S, Hida K, Kawada K, Sakai Y, Sugihara K. Role of repeat resection in patients with metastatic colorectal cancer: a multicenter retrospective study. Dis Colon Rectum. 2019;62:561-7.

7. Hachimaru A, Maeda R, Suda T, Takagi Y. Repeat pulmonary resection for recurrent lung metastases from colorectal cancer: an analysis of prognostic factors. Interact CardioVasc Thorac Surg. 2016;22:826-30.

8. Ogata Y, Matono K, Hayashi A, Tkamor S, Miwa K, Sasatomi T, et al. Repeat pulmonary resection for isolated recurrent lung metastases yields results comparable to those after first pulmonary resection in colorectal cancer. World J Surg. 2005;29:363-8.

9. Welter S, Jacobs J, Krbek T, Krebs B, Stamatis G. Long-term survival after repeated resection of pulmonary metastases from colorectal cancer. Ann Thorac Surg. 2007:84:203-10.

10. Liden PA, Yeap BY, Chang MY, Henderson WG, Jaklitsch MT, Khuri S, et al. Morbidity of lung resection after prior lobectomy: results from the veterans affairs National Surgical Quality Improvement Program. Ann Thorac Surg. 2007:83:425-32.

11. Adebonojo S, Mortiz D, Danby C. The results of modern surgical therapy for multiple primary lung cancers. Chest. 1997;112:693-701.

12. Asaph J, Keppel J, Handy J, Douville E, Tsen A, Ott G. Surgery for second lung cancers. Chest. 2000;118:1621-5.

13. Battafarano R, Force S, Meyers B, Bell J, Guthrie TJ, Cooper JD, et al. Benefits of resection for metachronous lung cancer. J Thorac Cardiovasc Surg. 2004;127:836-42.

14. Van Bodegom PC, Wagenaar SS, Corrin B, Baak JP, Berkel J, Vanderschueren RG. Second primary lung cancer: importance of long term follow up. Thorax. 1989;44:788-93.

15. Mckenna RJ Jr, Houck W, Fuller CB. Video-assisted thoracic surgery lobectomy: experience with 1,100 cases. Ann Thorac Surg. 2006;81:421-6.

16. Flores RM, Park BJ, Dycoco J, Aronova A, Hirth Y, Rizk NP, et al. Lobectomy by video-assisted surgery (VATS) versus thoracotomy for lung cancer. J Thorac Cardiovasc Surg. 2009;138:11-8.

17. Whitson BA, Groth SS, Duval SJ, Swanson SJ, Maddaus MA. Surgery for early-stage non-small cell lung cancer: a systematic review of the video-assisted thoracoscopic surgery versus thoracotomy approaches to lobectomy. Ann Thorac Surg. 2008;86:2008-18.

18. Sakuraba M, Miyamoto H, Oh S, Shiomi K, Sonobe S, Takahashi N, et al. Video-assisted thoracoscopic lobectomy vs. conventional lobectomy via open thoracotomy in patients with clinical stage IA non-small cell lung carcinoma. Interact Cardiovasc Thorac Surg. 2007;6:614-7.

19. Rizk NP, Ghanie A, Hsu M, Bains MS, Downey RJ, Sarkaria IS, et al. A prospective trial comparing pain and quality of life measures after anatomic lung resection using thoracoscopy or thoracotomy. Ann Thorac Surg. 2014;98:1160-6.

20. Shao C, Zheng C, Yan W, Shen Y, Zhang Z. Evaluation of efficacy and safety of minimally invasive segmentectomy in the treatment of lung cancer. Oncol Lett. 2018;15:9516-22.

21. Brinkman GL, Coates EO. The effect of bronchitis, smoking, and occupation on ventilation. Am Rev Respir Dis. 1963;87:684-93.

22. Katayama H, Kurokawa Y, Nakamura K, Ito H, Kanemitsu Y, Masuda N, et al. Extended Clavien-Dindo classification of surgical complications: Japan Clinical Oncology Group postoperative complications criteria. Surg Today. 2016:46:668-85.

23. Kobayashi Y, Arimoto H, Watanabe S. Occurrence of multiple primary cancer at the National Cancer Center Hospital, 1962-1989. Jpn j Clin Oncol. 1991;21:233-51.

24. Reinmuth N, Stumpf A, Stumpf P, Muley T, Kobinger S, Hoffmann H, et al. Characteristics and outcome of patients with second primary lung cancer. Eur Respir J. 2013;42:1668-76.

25. Tanvetyanon T, Robinson LA, Schell MJ, Strong VE, Kapoor R, Coit DG, et al. Outcomes of adrenalectomy for isolated synchronous versus metachronous adrenal metastases in non-small-cell lung cancer: a systematic review and pooled analysis. J Clin Oncol. 2008;26:1142-7.

26. Voltolini L, Rapicetta C, Luzzi L, Ghiribelli C, Paladini P, Granato F, et al. Surgical treatment of synchronous multiple lung cancer located in a different lobe or lung: high survival in node-negative subgroup. Eur J Cardiothorac Surg. 2010;37:1198-204.

27. Melloni G, Bandiera A, Gregorc V, Carretta A, Ciriaco P, Viganò M, et al. Combined treatment of non-small cell lung cancer with synchronous brain metastases: a single center experience. J Cardiovasc Surg (Torino). 2011:52:613-9.

\section{Publisher's Note}

Springer Nature remains neutral with regard to jurisdictional claims in published maps and institutional affiliations.
Ready to submit your research? Choose BMC and benefit from:

- fast, convenient online submission

- thorough peer review by experienced researchers in your field

- rapid publication on acceptance

- support for research data, including large and complex data types

- gold Open Access which fosters wider collaboration and increased citations

- maximum visibility for your research: over $100 \mathrm{M}$ website views per year

At BMC, research is always in progress.

Learn more biomedcentral.com/submissions 